\title{
PUERTO RICO: \\ "ENFERMERIA Y CHOQUE DEL FUTURO" *
}

Olga Rusa Lugo *

RBEn/01

LOCO, O.R. - Puerto Rico: "enfermeria g choque del futuro". Rev. Bras. Enf.; DF, $28: 127-131,1980$.

Yo, Olga Rosa Lugo, por voluntad de Cristo me complace encontrarme con ustedes en este Congreso, para tratar sobre la gran problemática que se vislumbra para la enfermería de hoy ante un futuro cambiante. El tema seleccionado ocupa nuestro interés porque somos parte integrante de este mundo camblante, donde la fuerza tecnológica ha motivado cambios a tan alta velocidad que nos ha abligado a sentarnos para deliberar sobre nuestra razón de ser hoy y de estar mañana.

Hermanos de las Américas, porque nos ha tocado vivir algo de los dramáticos acontecimientos de la evolución y la revolución de nuestro mundo, todos somos en mayor o menor grado actores I responsables del choque del futuro. La forma que habrá de adoptar la enfermería del mañana es responsabilidad de todos.

Nuestra posición con respecto al cambio es la siguiente. Creemos en el cambio porque implica movimiento, modificación y transformación. Creemos en el cambio evolutivo porque es ordenado y contínuo en una dírección determinada, porque entraña el desarrollo de fuerzas potencialmente presentes desde el comienzo. Detestamos el cambio violento y súbito, porque es seguido de situaciones de desequilibrio, inestabilidad y desorganización. Creemos en el cambio tecnológico como fuerza permanente de la historla de un pueblo que combina o totaliza aquellas técnicas, que emplea en un período determinado, con el fin de lograr la adaptación a su medio biofísico. El cambio tecnológico ordenado debe propiciar un equilibrio 0 ajuste entre un medio dado con sus recursos potenciales, y el pueblo que habita dicho medio, con sus capacidades y conocimientos técnicos. Opinamos, con mesura, sobre el cambio revolucionario y creemos que merece nuestra atención, ya que es un cambio importante porque

\footnotetext{
- Terna apresentado no 5.0 Congresso da Federação Panamericana de Enfermelras(os) - Porto Rlco - Abrll, 1979.
} 
LUGO, O.R. - Puerto Rico: "enfermeria g choque del futuro". Rev. Bres. Enf.; DF, $33: 127-131,1980$.

afecta 0 altera las relaciones reciprocas de las clases sociales, así como las ideas, tradiciones, adscripciones, que sirven de soporte a la estructura social. El proceso final en el cambio revolucionario, viene precedido de ordinario, por un largo periodo de fermentación y agitación intelectual, que prepara el terreno al momento, crisis o luchas revolucionarias.

¿Cómo visualizamos la enfermería de hoy ante el choque del futuro?

Los profesionales de enfermería no estamos inmunes a los problemas que encara nuestra sociedad moderna. Somos proveedores de los servicios necesarios para la prevención, control y tratamiento de la patología resultante a una sociedade críticamente enferma por el síndrome del cambio. Somos también vulnerables a esta era de ansiedad y tensión, pruducida por los cambios violentos y súbitos, producto de la tecnología. Una ojeada a la situación social de la enfermería de nuestros tiempos, nos arrojará un caudel de información, que amerita ser analizado y que puede ser común a todos los países aquí representados. En todos los países de gobiernos democráticos las enfermeras (os), al igual que todo hombre o mujer moderno reclaman el derecho constitucional de auto-realización e identidad propia. Este reclamo responde al concepto filosófico existencialista que sostiene, que cada individuo es libre y responsable del desarrollo de su propia esencia. En la forma cristiana esta teoría de auto-realización conduce a una felicidad eterna, Dios, supremo Creador. En las dos formas, se defiende el principio de libertad que tiene el ser humano, para buscar todos los medios disponibles de desarrollo propio y auto-realización, en unidad con la esencia del universo que le rodea. Es Imprescindible un intercambio dinámico entre hombre, mundo y viceyersa, para el logro de una identidad propria.
¿Qué sucede en nuestro mundo tal como lo presenta el autor del libro; "El Choque del Futuro? ¿Qué le sucede al hombre actor y responsable, juez y parte de este mundo?

El mundo se presenta contaminado por demasiados cambios, introducidos sin control, por una tecnología que ha precipitado un estado de choque.donde sus víctimas somos tú y yo, hombre y mujer del presente. Los cambios drásticos en su naturaleza, han convertido, lo permanente en temporal incluso en las relaciones humanas. El hombre, 11bre por naturaleza divina, se convierte en promotor y cautivo de una tecnología que lo ha abocado a la deshumanización.

¿Cómo se perfila la Enfermería dentro de este mundo cambiante?

Una declaración honesta de la situación de la enfermería, necesariamente tiene que revelar, que la misma por tiempo considerable, se ha sentido amenazada por una serie de sucesos, de origen interno unos $y$ otros del ambiente que le rodea. Los ejemplos que entre otros vamos a citar, pueden der experiencias de todos.

\section{No. 1 Lucha de clases}

La profesión de la enfermería, en su cometido de producir personal para las demandas que le impone la sociedad, se precipitó en el establecimiento y proliferación de programas de enfermeria a diferentes niveles, en. Universidades, Colegios y Escuelas Vocacionales, sin preocuparse antes por una Legislación para ligitimar los títulos académicos otorgados en estos programas. Esto ha aado margen a que bajo un solo título profesional se haya tenido que proteger legalmente a más de un $70 \%$ de estas personas, quienes en su preparación difieren notablemente. Es lógico 
LUGO, O. R. - Puerto Rico: "enfermeria y choque del futuro". Rev. Bras. Enf.; DF, $33: 127-131,1980$.

pensar el malestar que se ha desarrollado en estos profesionales, porque sin lugar a dudas, se han violentado los derechos de los afectados. Esta situación ha desatado pugnas internal entre los miembros afectados por razones de funciones, pocisiones y salarios.

No. 2 La inconsistencia en los programas de estudios y los cambios drásticos en el contenido

En una población de tres millones y medio de habitantes, en un territorio de $100 \times 35$ millas cuadradas, si hacemos un estudio del contenido del programa de estudios de enfermería en escuelas que otorgan títulos académicos similares, encontramos más diferencias que analogías. Esta situación no favorece a los graduados de estos programas, porque las agencias, al emplearlos, establecen diferencias en términos de la preparación y ejecución, calificándolos en categorias de superior e inferior preparación. Es muy común el estribillo aún entre los miembros de la profesión y cito "Estos graduandos de hoy y de tal programa, no sirven para nada, prefiero los de tal.

Los cambios drásticos en el contenido de los programas son sumamente dañinos. Podemos citar la experiencia de una institución educativa, dónde en menos de tres años, se pusieron a circular tres programas de estudio de diferente diseño, para un sólo título académico. Sin dar lugar a la terminación de un programa nuevo iniciado, y la evaluación de ese producto, en contra del consejo y consentimiento de la Facultad y estudiantes, administrativamente, se inició otro programa de estudios. El resultado de esta situación ya pueden inferir ustedes, lo identificamos como un estado de choque con daños irreversibles para facultad y estudiantes.
No. 3 La separación de Educación y Servicio en Enfermeria

Es nuestra opinión, que la separación de educación y servicio, para los fines de formación de estudiantes y cuidado de pacientes no ha logrado un estado satisfactorio de armonía y equilibrio. Consideramos muy poco afortunado, el ambiente que permea entre educadores en efremería y el personal del servicio. Creemos que las emociones más que la objetividad predominan en las relaciones. Si exploramos las reacciones emocionales experimentadas por las personas' en ambas categorias, encontraremos lo siguiente. Las dos, sienten que han pérdido "status"; la supervisora cree que ha pérdido autoridad sobre el estudiante y la educadora sobre el paciente. El personal en servicio de enfermeria, considera que ha perdido el recurso del estudiante para el cuidado del paciente, y se considera como víctima de la educación.

La educadora que antes se sentía en libertad para usar el escenario clínico, como laboratorio para el aprendizaje del estudiante, ahora se siente como una visitante, en ocasiones muy inoportuna, y con limitaciones para actuar. El hecho de que los líderes en la profesión hayan hecho hincapié, en la importancia de la preparación de la enfermera a nivel de la educación superior, para hacer frente a las demandas de esta sociedad cambiante, ha provocado malestar en el personal de enfermería que carece de esta preparación, porque se sienten relegadas a un segundo plano.

Como resultado de lo último, se ha iniciado un movimiento a todo vapor demandando el establecimiento y proliferación de programas a nivel de educación superior para enfermeras(os) ya licenciados. La dinámica del movimiento a veces sugiere una nueva generación en enfermería educada con cambios a alta velocidad. 
LUGO, O.R. - Puerto Rico: "enfermera y choque del futuro". Rev. Bras. Enf.; DF, $33: 127-131,1980$.

No. 4 La calidad de los servicios de Enfermeria

La profesión de la enfermería arribó al climax de su existencia. La supervivencia de la enfermería, como un componente vital de las profesiones de la salud dependerá en gran medida, de la decisión de sus miembros por la excelencia o, lo anticuado y obsoleto. La opción por lo anticuado y obsoleto no requiere cambio direccional alguno; sólo una resistencia pasiva al cambio, evitando un acercamiento intelectual de razonamiento lógico a los problemas clínicos de enfermería y optar por una devoción a los detalles administrativos de las agencias de salud.

El optar por lo anticuado y obsoleto tendrá un equivalente a seguir la línea de menor resistencia y mantener un estado de ningún envolvimiento. La opción por la excelencia es mucho más rigurosa; requiere una mente más inquisitiva, iluminada por los descubrimientos científicos, tecnológicos y contemporáneos en el campo de la salud y enfermedad y en todas las ciencias del saber y la conducta humana, y de manera significativa, un cuerpo de conocimientos propio de la ciencia y el arte de la enfermeria. En adición a ésto va el alto sentido de responsabilidad ciudadana y envolvimiento y compromiso profesional.

En los últimos tíempos la calidad y la excelencia de los servicios de enfermeria se ha visto amenazada y fuertemente criticada por los consumidores. ¿A quién le daremos la razón? Los resultados estadísticos en una encuesta hipotética nos arrojará evidencia para inferir que, en términos de la opción entre la excelencia y lo anticuado y obsoleto de los servicios de enfermería, el consenso de opiniones está compartido. Compañeros ciudadanos de las Américas, son muchas las experiencias, que se podrian citar aqui, de aquellos colegas, que voluntariamente están bajo la opresión de la bota y el yugo de los gigantes de la salud, tanto en el servicio como en educación. Muchos han optado por la línea de menor resistencia, porque tienen ojos y no quieren ver, tienen oídos y no quieren escuchar, tienen lengua y no quieren hablar y tienen masa encefálica pero no quieren pensar. Estas son las víctimas No. 1 del Choque del Futuro. Están haciendo punto en otro son.

\section{No. 5 Las condiciones de empleo y sueldo}

En la actualidad se habla de un éxodo del personal de enfermería hacia otras profesiones ou ocupaciones. Las razones para el éxodo pueden ser muchas, pero entre otras mencionaremos las más verbalizadas. La multiplicidad de tareas tanto administrativos como técnicas que han sobrecargado las legítimas funciones de la enfermera y la han retirado del cuidado directo al paciente. Las condiciones de empleo son tan poco atractivas, que la salud física y mental de la enfermera va en deterioro. Los salarios devengados no son equitativos con la preparación académica que se le exige al profesional, ni con el nivel de vida que estamos viviendo. Esta situación sin precedentes también se repite en la docencia, donde la tarea académica se sobrecarga con funciones administrativas a tal extremo que se ha puesto en peligro la calidad y excelencia de la labor pedagógica.

No. 6 La politización en todos los ámbitos de la enfermeria

Una revolución politica, interna en forma silente, muy pocas veces verbalizadas se ha infiltrado a nivel de estructura y organización de enfermería, tanto en el servicio como en la educación. Parece que enfermería por ser la población más numerosa entre las profesiones de la salud se ha convertido, 
LUGO, O.R. - Puerto Rico: "enfermeria y choque del futuro". Rev. Bras. Enf.; DF, $33: 127-131,1980$.

en un organismo codiciado por las diferentes denominaciones políticas. Es posible que de ahora en adelante aparezcan muchos "San Nicolás", en el panorama de la enfermería. Causa impacto al observador porque, por haber sido históricamente una organización de creảos e ideales heterogéneos de gran respeto profesional entre sí, no anticipábamos la contienda política como agentc destructor de nuestros lazos de unidad y confraternidad.

No. 7 Los derechos profesionales violentados

Los derechos profesionales de la Enfermería, hoy más que nunca, se están violentando por individuos ajenos a nuestra disciplina. Compañeros, es difícil tener que aceptar una realidad tan dolorosa; pero vanos han resultado los esfuerzos que se han venido realizando por lograr una profesión independiente, y liberada de las fuerzas opresoras de los gigantes de la solud que insisten en seguir subyugando a la enfermería. En nuestros esfuerzos aún estamos en ciernes. En este momento queremos hacernos eco de las palabras que dirigiera e] Sr. Luis Ramos, Presidente del Colegio de Profesionales. de la Enfermería de Puerto Rico, en su mensaje a la Sesión Administrativa de la Asamblea anual del Colegio en diciembre del 1978 y cito "Actualmente se están tomando decisiones en enfermería por miembros de nuestra sociedad ajenos a nuestra pro- fesión, en los renglones más vitales de nuestra educación futura, de nuestras condiciones de trabajo, y de las escalas salariales" (Cierro la cita). Es evidente que en nuestra sociedad, hay elementos que no quieren entender que las enfermeras y los enfermeros, al igual que los que hoy nos oprimen, tenemos derechos a buscar las maneras de identidad propia, de auto-realización y de la unidad con la esencia del universo que nos rodea. Consideramos que los lazos que nos oprimen por parte de nuestra sociedad en estos momentos, están precipitando a la enfermería a reacciones drásticas. ¿Cuál ha de ser nuestra postura frente al choque del Futuro?

Hermanos de las Américas, la Enfermería de hoy sin más ambajes se proyecta hacia el futuro, en un estado de fermentación. En el inicio de esta presentación mencionamos que el estado de fermentación es propio del cambio revolucionario. Hacemos un llamado a los profesionales de la enfermería para que con mesura, cordura y firmeza, se lancen a la batalla para rescatar la verdadera imagen de la enfermería que ha de ser, la de un profesional intelectual, por sus méritos respetado, justamente salariado, y totalmente liberado. Como hombres y mujeres de fé arraigada libraremos la batalla con Cristo a la vanguardia, repitiendo con El "No penséis que he venido a abolir la Ley y los Profetas. No he venido a abolir sino a dar cumplimiento". Mateo 5-17. 